\title{
HDL-C and non-HDL-C levels are associated with anthropometric and biochemical parameters
}

\author{
Associação de níveis de HDL-c e não HDL-c com parâmetros antropométricos e \\ bioquímicos
}

Sandra Maria Barbalho',2 (D), Ricardo José Tofano', Marcela Bueno de Oliveira', Karina Rodrigues Quesada', Mariana Ricci Barion ${ }^{1}$, Marina Cristina Akuri', Marie Oshiiwa², Marcelo Dib Bechara ${ }^{1}$

\begin{abstract}
Background: Dyslipidemias are associated with atherosclerosis and cardiovascular diseases. Recently, non-high-density lipoprotein cholesterol (non-HDL-c) has emerged as a new target for assessment and prediction of risk of cardiovascular disease (CVD) and is closely associated with atheroma plaque progression. Objectives: To evaluate associations between HDL-c and non-HDL-c levels and anthropometric and biochemical parameters and with the Castelli risk indexes I and II. Methods: 300 randomly selected people were subdivided into two groups: patients with normal values for non-HDL-c and patients with altered values for non-HDL-c. These parameters were analyzed for associations with glycemia, total cholesterol (TC), triglycerides (TG), low-density lipoprotein (LDL-C), Castelli Index I (Cl-I), Castelli Index II (CI-II), waist circumference (WC), body mass index (BMI) and presence of metabolic syndrome (MS). Results: Glycemia, TC, TC, LDL-C, CI-I, CI-II, WC and BMI were all significantly different between subjects with normal and altered values of HDL-C and non-HDL-C. TC and WC both exhibited significantly higher values among patients with abnormal non-HDL-c when compared to patients with abnormal HDL-c. A significant difference was observed in occurrence of MS among patients with altered values of HDL-c and non-HDL-c. Conclusions: Our results show that both HDL-c and non-HDL-c are associated with insulin resistance, dyslipidemia, atherogenic indices, and obesity. There is therefore a need for randomized clinical intervention trials examining the potential role of non-HDL-c as a possible primary therapeutic target.
\end{abstract}

Keywords: non-HDL-c; glycemia; dyslipidemia; metabolic syndrome.

\begin{abstract}
Resumo
Contexto: A dislipidemia está associada à aterosclerose e às doenças cardiovasculares. Recentemente, a lipoproteína de não alta-densidade de colesterol (não HDL-c) emergiu como um novo alvo para avaliação da predição de risco de doença cardiovascular, intimamente associada à progressão da placa de ateroma. Objetivos: Avaliar as associações de níveis de HDL-c e não HDL-c com parâmetros antropométricos e bioquímicos, bem como com índices de Castelli l e ll (Cl-l e Cl-II). Métodos: Trezentas pessoas selecionadas aleatoriamente foram divididas em dois grupos: pacientes com valores normais de não $\mathrm{HDL}-\mathrm{c}$ e pacientes com valores alterados de não $\mathrm{HDL}-c$. Esses parâmetros foram associados a glicemia, colesterol total (CT), triglicerídeos (TG), lipoproteína de baixa densidade (LDL-C), CI-I, CI-II, circunferência de cintura (CC), índice de massa corporal (IMC) e presença de síndrome metabólica (SM). Resultados: Clicemia, CT, TC, LDL-C, Cl-I, CI-II, CC e IMC exibiram valores significativamente maiores para o não HDL-c quando comparado ao HDL-c. Uma diferença significativa na ocorrência de SM foi encontrada em pacientes com valores alterados de HDL-c e não HDL-c. Conclusões: Nossos resultados mostram que tanto o HDL-c quanto o não HDL-c estão associados a resistência à insulina, dislipidemia, índices de aterogênese e obesidade. Assim, há uma necessidade de futuros ensaios randomizados de intervenção clínica examinando o papel potencial do não HDL-c como possível alvo terapêutico primário.
\end{abstract}

Palavras-chave: não HDL-c; glicemia; dislipidemia; síndrome metabólica.

How to cite: Barbalho SM, Tofano RJ, Oliveira MB, et al. HDL-C and non-HDL-C levels are associated with anthropometric and biochemical parameters. J Vasc Bras. 2019;18:e20180109. https://doi.org/10.1590/1677-5449.180109

\footnotetext{
${ }^{1}$ Universidade de Marília - UNIMAR, Faculdade de Medicina, Departamento de Bioquímica e Farmacologia, Marília, SP, Brasil.

${ }^{2}$ Faculdade de Tecnologia - Fatec Marília, Departamento de Bioquímica e Nutrição, Marília, SP, Brasil.

Financial support: None.

Conflicts of interest: No conflicts of interest declared concerning the publication of this article.

Submitted: November 05, 2018. Accepted: February 08, 2019.
} 


\section{INTRODUCTION}

Dyslipidemias are major risk factors for development of atherosclerosis and cardiovascular diseases (CVD). They are associated with formation of atherosclerotic plaques, which build up in the intima of the vessel and can influence increased risk for cardiovascular events. Many risk factors play fundamental roles in dyslipidemias, including smoking, obesity, physical inactivity, high blood pressure, insulin resistance, and environmental and genetic influences. ${ }^{1-5}$

CVD is strongly associated with the Metabolic Syndrome (MS), which comprises a series of risk factors associated with high morbidity. The etiology of MS involves genetic, metabolic and environmental factors and it usually manifests with insulin resistance and abnormal values of HDL-c, triglycerides (TG), waist circumference (WC), blood pressure, and C-reactive protein (CRP), in addition to obesity. ${ }^{1}$

Atherosclerosis is associated with hypertriglyceridemia, low HDL-c levels, qualitative changes in LDL particles, accumulation of remnant lipoproteins, and postprandial hyperlipidemia. ${ }^{1,2}$

Recently, non-High-Density Lipoprotein cholesterol (non-HDL-c) has emerged as a new target for the prevention of cardiovascular events. It reflects the full burden of the cholesterol transported in atherogenic lipoproteins, it is crucial to prediction of CVD risk, ${ }^{3}$ and it is closely associated with plaque progression. ${ }^{4,5}$

Non-HDL-c comprises the cholesterol carried by all potentially atherogenic particles, including LDL-c, intermediate density lipoproteins, very low-density lipoproteins, and remnant lipoproteins. Several meta-analyses found that non-HDL-c correlated more closely with cardiovascular risk than LDL-c, both at baseline and during therapy. ${ }^{6-8}$

Routes to earlier detection of CVD such as high sensitivity C-reactive protein, carotid intima-media thickness, and coronary artery calcium are among the various measures that can be used to screen for CVD in asymptomatic populations. ${ }^{5}$ The atherosclerosis guidelines of the Brazilian Cardiology society, in common with other global guidelines, indicate that
non-HDL-c is relevant to prevention and is a therapeutic target for management of CVD..$^{6-8}$

This study aimed to evaluate associations between HDL-c and non-HDL-c levels and anthropometric and biochemical parameters in a group of patients.

\section{METHODS}

The study population comprised 300 people who were included in our study after signing consent forms (in accordance with the Helsinki Declaration).

Participants were divided into two groups: patients with normal HDL-c and non-HDL-c levels and patients whose test results were abnormal.

All participants underwent a physical examination, including measurement of height, weight, and waist circumference (WC). Body mass index (BMI) was evaluated as weight in kilograms divided by height in square meters. ${ }^{1}$ The anthropomorphic measurements weight, height, and $\mathrm{WC}$ were obtained using techniques recommended by Gibson. ${ }^{2}$ For evaluation of anthropometric parameters, we used a digital scale (FILIZOLA ${ }^{\circledR}$ with capacity for $150 \mathrm{~kg}$ ) and a fixed stadiometer with a metric scale, positioned on a flat surface.

Glycemia, total cholesterol (TC), triglycerides (TG), and low-density lipoprotein (LDL-c) levels, waist circumference (WC), body mass index (BMI), and presence/absence of metabolic syndrome (MS) were also evaluated. The Castelli Risk Index I (CI-I) and Castelli Risk Index II (CI-II) were also considered. These two evaluations are derived from TC/HDL-c and LDL-c/HDL-c respectively. Values of HDL-c lower than $40 \mathrm{mg} / \mathrm{dL}$ for men and $50 \mathrm{mg} / \mathrm{dL}$ for women were considered altered.

Student's $t$ test was used to compare parametric data and the Mann Whitney test was used for nonparametric data, with a significance level of $5 \%(\mathrm{p}<0.05)$.

\section{RESULTS}

Table 1 lists the biochemical and anthropometric parameters for the patients, grouped by normal or abnormal HDL-c and non-HDL-c levels. Glycemia,

Table 1. Biochemical parameters according to classification by HDL-c and non-HDL-C.

\begin{tabular}{|c|c|c|c|c|}
\hline \multirow{2}{*}{ Parameters } & \multicolumn{2}{|c|}{ HDL-c } & \multicolumn{2}{|c|}{ Non-HDL-c } \\
\hline & Normal & Altered & Normal & Altered \\
\hline Glycemia & $109.3 \pm 26.2 \mathrm{~A}$ & $133.6 \pm 14.43 \mathrm{~B}$ & $111.0 \pm 21.9 \mathrm{~A}$ & $134.2 \pm 13.8 \mathrm{~B}$ \\
\hline $\mathrm{TC}$ & $188.9 \pm 31.1 \mathrm{BC}^{*}$ & $186.8 \pm 42.34 \mathrm{~B}$ & $143.0 \pm 21.73 \mathrm{~A}$ & $207.7 \pm 31.0 \mathrm{C}$ \\
\hline TG & $112.7 \pm 21.4 \mathrm{~A}$ & $147.5 \pm 24.9 B$ & $115.6 \pm 51.4 \mathrm{~A}$ & $158.4 \pm 91.5 \mathrm{~B}$ \\
\hline LDL-C & $97.6 \pm 34.1 \mathrm{~A}$ & $121.9 \pm 24.2 \mathrm{~B}$ & $74.5 \pm 20.0 \mathrm{~A}$ & $127.8 \pm 41.2 \mathrm{~B}$ \\
\hline $\mathrm{Cl}-\mathrm{I}$ & $2.8 \pm 0.6 \mathrm{~A}$ & $4.8 \pm 2.1 \mathrm{~B}$ & $3.3 \pm 0.8 \mathrm{~A}$ & $5.2 \pm 2.2 \mathrm{~B}$ \\
\hline $\mathrm{Cl}-\mathrm{II}$ & $1.5 \pm 0.6 \mathrm{~A}$ & $2.9 \pm 2.0 \mathrm{~B}$ & $1.7 \pm 0.6 \mathrm{~A}$ & $3.3 \pm 2.1 \mathrm{~B}$ \\
\hline WC & $91.0 \pm 14.0 \mathrm{~A}$ & $109.1 \pm 9.5 \mathrm{~B}$ & $92.0 \pm 15.8 \mathrm{~A}$ & $129.6 \pm 6.6 \mathrm{C}$ \\
\hline $\mathrm{BMI}$ & $27.5 \pm 3.4 \mathrm{~A}$ & $31.3 \pm 3.6 \mathrm{AB}$ & $27.8 \pm 4.9 \mathrm{~A}$ & $31.9 \pm 5.7 \mathrm{~B}$ \\
\hline
\end{tabular}

*Different letters indicate a significant difference between groups to a level of $5 \%$; same letters for different groups indicate no significant difference. TC = Total Cholesterol; TG = Triglycerides; HDL-c = High-Density Lipoprotein; LDL-C = Low-Density Lipoprotein; Castelli Index I = TC/HDL-c; Castelli Index II = LDL-c/HDL-C; WC = Waist Circumference; BMI = Body Mass Index. 
Table 2. Presence of Metabolic Syndrome by normal and altered HDL-c and non-HDL-c levels (\%).

\begin{tabular}{|c|c|c|c|c|}
\hline \multirow{2}{*}{ MS } & \multicolumn{2}{|c|}{ HDL-C } & \multicolumn{2}{|c|}{ non-HDL-c } \\
\hline & Normal & Altered & Normal & Altered \\
\hline No & $43.5 \%$ & $28.3 \%$ & $44.9 \%$ & $21.8 \%$ \\
\hline Yes & $56.5 \%$ & $71.7 \%$ & $55.1 \%$ & $78.2 \%$ \\
\hline$p$-value & 0.6767 & 0.0000 & 0.3964 & 0.0000 \\
\hline
\end{tabular}

TC, TG, LDL-c, CI-I, CI-II, WC, and BMI were all significantly different between patients with normal and altered HDL-c and non-HDL-c levels. TC and WC both exhibited significantly higher values among patients with abnormal non-HDL-c when compared to patients with abnormal HDL-c.

Table 2 shows that there were significant differences in the proportion of patients with altered values of HDL-c and non-HDL-c between those with Metabolic Syndrome and those without.

\section{DISCUSSION}

In our study, we observed that altered values for both HDL-c and non-HDL-c were related to higher values for glycemia, TC, TG, LDL-c, CI-I, CI-II, WC, and BMI. Presence of MS was also associated with altered values for HDL-c and non-HDL-c.

Recently the International Atherosclerosis Society (2015) and the Brazilian dyslipidemia guidelines (2017) have flagged non-HDL-c as the primary form of atherogenic cholesterol and a therapeutic target. ${ }^{6-8}$ The guideline recommendation is to use non-HDL-c as a parameter for evaluation of dyslipidemias, especially in patients with higher triglycerides levels $(>400 \mathrm{mg} / \mathrm{dL})$. This update maintains the recommendation of achieving levels of LDL-c, the primary target, and non-HDL-c, the secondary target, according to cardiovascular risk. The purpose of using non-HDL-c is to estimate the quantity of circulating atherogenic lipoproteins in plasma, especially in subjects with high TG. ${ }^{6}$

Hypercholesterolemia is a clinical condition that may be interrelated with oxidative stress, insulin resistance, hyperglycemia, obesity, and MS. Prognosis includes development of diabetes mellitus, endothelial dysfunction, and atherosclerosis. The relationship between an atherogenic lipid profile and high plasma triglycerides contributes to progression of atherosclerosis. ${ }^{6-8}$ For this reason, evaluation of non-HDL-c could play an essential role in the prevention of vascular events.

Non-HDL-c is considered a valuable predictor of premature atherosclerosis and coronary events such as myocardial infarction and cardiovascular mortality. ${ }^{9}$ It represents the sum of all lipoproteins with atherogenic properties and so, in other words, non-HDL-c consists of atherogenic remnants. $4,6,10,11$
Some studies suggest that aiming to reduce non-HDL-c and disregarding other lipid parameters might be a better approach, because patients with elevated non-HDL-c had a higher risk of cardiac events than those with elevated TG or with high LDL-c., ${ }^{, 12-15}$

Our results show that higher non-HDL-c levels were associated with higher LDL-c levels. Authors have suggested that non-HDL-c levels may reflect the risk of CVD better than LDL-c alone. Furthermore, the connection between atherogenic lipoprotein phenotypes (non-HDL-c) and obesity is more relevant than the connection with LDL-c. ${ }^{6,9,16}$

As can be observed in Table 1, TG values were significantly higher among those with altered non-HDL-c compared to those with normal non-HDL-c. It is known that the association between non-HDL-c and high TG levels can be described as the co-occurrence of hypertriglyceridemia, low HDL-c, and high levels of small dense-LDL particles. ${ }^{9}$ Concomitant increase of plasma TG and apo-B levels accounts for dyslipoproteinemia that is determinant of both DM and MS. ${ }^{6,9}$

The Castelli Risk Indexes I and II can also be used for assessment of cardiovascular risk. ${ }^{1}$ There were statistically significant differences in CI-I and CI-II between subjects classified as having normal and altered HDL-c and non-HDL-c (Table 1), indicating that assessment of these indices may be of help in clinical management. To the best of our knowledge, there are no studies involving Castelli indexes and non-HDL-c.

Values for non-HDL-c are also closely linked to visceral obesity. ${ }^{17}$ Our data showed that non-HDL-c is associated with waist circumference.

Studies have shown that patients with MS have higher non-HDL-c levels. ${ }^{9,15,16}$ In our study, the proportions of patients with altered HDL-c and non-HDL-c levels were significantly higher among patients with MS than among patients without MS. The mechanisms linking non-HDL-c to MS have not been thoroughly explained, but low-grade inflammation, a pro-coagulatory state, thrombosis, and other cardiovascular complications should all be considered.

Studies have shown that high levels of non-HDL-c were associated with higher odds of developing metabolic 
syndrome, independent of central obesity and insulin resistant states ${ }^{6,9,14-16}$ and high non-HDL-c levels are a direct cause of atherosclerosis. This aggression to the vascular endothelium is a risk factor for stroke and cardiovascular morbidity and mortality. ${ }^{18-20}$

Panazzolo et al. ${ }^{21}$ showed in non-diabetic women that a multivariate scenario of relations between parameters related to obesity and MS indicates an important association between these pathologies and microvascular reactivity.

Kraemer-Aguiar et al. ${ }^{22}$ suggested that obesity is sufficient to result in impairment of vascular reactivity, and that BMI may positively correlate with worsening of endothelium changes.

In line with the literature, our study shows that elements of the atherogenic lipid profile may assist in achieving clinical goals including prevention and early diagnosis of CVD events. Our results show that both HDL-c and non-HDL-c are associated with insulin resistance, dyslipidemia, atherogenic indices, and obesity. There is therefore a need for randomized clinical intervention trials examining the potential role of non-HDL-c as a possible primary therapeutic target.

\section{REFERENCES}

1. Barbalho S, Tofano RJ, Bechara MD, Quesada K, Coqueiro DP, Mendes CG. Castelli Index and estimative of LDL-C particle size may still help in the clinical practice? J Cardiovasc Dis Res. 2016;7(2):86-9. http://dx.doi.org/10.5530/jcdr.2016.2.6.

2. Alibasic E, Ramic E, Bajraktarevic A, Ljuca F, Batic-Mujanovic O, Zildzic $M$. Atherogenic dyslipidemia and residual vascular risk in practice of family doctor. Med Arh. 2015;69(5):339-41. http:// dx.doi.org/10.5455/medarh.2015.69.339-341. PMid:26622090.

3. Costa IFAF, Medeiros CCM, Costa FDAF, et al. Adolescentes: comportamento e risco cardiovascular. J Vasc Bras. 2017;16(3):20513. http://dx.doi.org/10.1590/1677-5449.011816. PMid:29930648.

4. Puri R, Nissen SE, Shao $M$, et al. Non-HDL cholesterol and triglycerides: Implications for coronary atheroma progression and clinical events. Arterioscler Thromb Vasc Biol. 2016;36(11):2220-8 http://dx.doi.org/10.1161/ATVBAHA.116.307601. PMid:27515380.

5. Zeb I, Budoff M. Coronary Artery calcium screening: does it perform better than other cardiovascular risk stratification tools? Int J Mol Sci. 2015;16(3):6606-20. http://dx.doi.org/10.3390/ijms16036606. PMid:25807266.

6. Faludi AA, Izar MCO, Saraiva JFK, et al. Atualização da Diretriz Brasileira de Dislipidemias e Prevenção da Aterosclerose - 2017. Arq Bras Cardiol. 2017;109(2, Suppl 1):1-76.

7. Grundy SM. An International Atherosclerosis Society Position Paper: global recommendations for the management of dyslipidemia. J Clin Lipidol. 2013;7(6):561-5. http://dx.doi.org/10.1016/j. jacl.2013.10.001. PMid:24314355.

8. Jacobson TA, Ito MK, Maki KC, et al. National lipid association recommendations for patient-centered management of dyslipidemia: part 1- full report. J Clin Lipidol. 2015;9(2):129-69. http://dx.doi. org/10.1016/j.jacl.2015.02.003. PMid:25911072.

9. Ghodsi S, Meysamie A, Abbasi M, et al. Non-high-density lipoprotein fractions are strongly associated with the presence of metabolic syndrome independent of obesity and diabetes. A population-based study among Iranian adults. J Diabetes Metab Disord. 2017;25(1):16-25. http://dx.doi.org/10.1186/s40200-0170306-6. PMid:28596946.

10. Fruchart JC, Davignon J, Hermans MP, et al. Residual macrovascular risk in 2013: what have we learned? Cardiovasc Diabetol. 2014;13(1):26. http://dx.doi.org/10.1186/1475-2840-13-26. PMid:24460800.

11. Wang D, Wang L, Wang Z, Chen S, Ni Y, Jiang D. Higher non$\mathrm{HDL}$-cholesterol to $\mathrm{HDL}$-cholesterol ratio linked with increased nonalcoholic steato hepatitis. Lipids Health Dis. 2018;17(1):67. http://dx.doi.org/10.1186/s12944-018-0720-x. PMid:29615042.

12. Bermúdez V, Torres W, Salazar J, et al. Non-HDL cholesterol is better than LDL-c at predicting atherosclerotic cardiovascular disease risk factors clustering, even in subjects with near-to-normal triglycerides: A report from a Venezuelan population. F1000 Res. 2018;7:504. http://dx.doi.org/10.12688/f1000research.13005.1.

13. Kumar VB, Guntakalla YR, Thomas Z, Rajasekaran UR, Gnanasekaran P. Role of Non High Density Lipoprotein Cholesterol (Non HDL-C) in predicting coronary artery disease. Indian J Pharmacy Practice. 2015;8(4):166-70. http://dx.doi.org/10.5530/ijopp.8.4.4.

14. Moriyama K, Takahashi E. Non-HDL Cholesterol is a more superior predictor of small-dense LDL Cholesterol than LDL Cholesterol in japanese subjects with TG levels $<400 \mathrm{mg} / \mathrm{dL}$. J Atheroscler Thromb. 2016;23(9):1126-37. http://dx.doi.org/10.5551/jat.33985. PMid:27001003.

15. Kim SW, Jee JH, Kim HJ, et al. Non-HDL-cholesterol/HDLcholesterol is a better predictor of metabolic syndrome and insulin resistance than apolipoprotein B/apolipoprotein A1. Int J Cardiol. 2013;168(3):2678-83. http://dx.doi.org/10.1016/j.ijcard.2013.03.027. PMid:23545148.

16. Gasevic D, Frohlich J, Mancini GJ, Lear SA. Clinical usefulness of lipid ratios to identify men and women with metabolic syndrome: a cross-sectional study. Lipids Health Dis. 2014;13(1):159. http:// dx.doi.org/10.1186/1476-511X-13-159. PMid:25300321.

17. Huang J, Parish R, Mansi I, et al. Non-high-density lipoprotein cholesterol in patients with metabolic syndrome. J Investig Med. 2008;56(7):931-6. http://dx.doi.org/10.2310/JIM.0b013e318182080a. PMid:18753978.

18. Furuhashi M, Saitoh S, Shimamoto K, Miura T. Fatty Acid-Binding Protein 4 (FABP4): pathophysiological insights and potent clinical biomarker of metabolic and cardiovascular diseases. Clin Med Insights Cardiol. 2015;8(Suppl 3):23-33. http://dx.doi.org/10.4137/ CMC.S17067. PMid:25674026

19. Ruan Y, Wei W, Yan J, et al. Time rate of blood pressure variation is associated with Endothelial Function in patients with metabolic syndrome. Int Heart J. 2016;57(2):226-33. http://dx.doi.org/10.1536/ ihj.15-322. PMid:26973261.

20. Kurkowska-Jastrzebska I, Karlinski MA, Błazejewska-Hyzorek B, Sarzynska-Dlugosz I, Filipiak KJ, Czlonkowska A. Carotid intima media thickness and blood biomarkers of atherosclerosis in patients after stroke or myocardial infarction. Croat Med J. 2016;57(6):54857. http://dx.doi.org/10.3325/cmj.2016.57.548. PMid:28051279.

21. Panazzolo DG, Sicuro FL, Clapauch R, Maranhão PA, Bouskela E, Kraemer-Aguiar LG. Obesity, metabolic syndrome, impaired fasting glucose, and microvascular dysfunction: a principal component analysis approach. BMC Cardiovasc Disord. 2012;12(1):102. http:// dx.doi.org/10.1186/1471-2261-12-102. PMid:23148545.

22. Kraemer-Aguiar LG, Miranda ML, Bottino DA, et al. Increment of body mass index is positively correlated with worsening of endothelium-dependent and independent changes in forearm blood flow. Front Physiol. 2015;6:223. http://dx.doi.org/10.3389/ fphys.2015.00223. 
Correspondence

Sandra Maria Barbalho

Universidade de Marília - UNIMAR, Faculdade de Medicina,

Departamento de Bioquímica e Farmacologia

Av. Higino Muzzi Filho, 1001

CEP 15525-902 - Marília (SP) - Brasil

Tel.: +55 (14) 99655-3190

E-mail:smbarbalho@gmail.com

Author information

SMB - PhD in Sciences, Universidade Federal de São Carlos (UFSCar).

RJT - Cardiologist, Unidade de Hemodinâmica, Associação Beneficente Hospital Universitário (ABHU)

MBO, MRB and MCA - Medical students, Universidade de Marília

(UNIMAR)

KRQ - MSc in Nutrition, Universidade Estadual Paulista "Júlio de

Mesquita Filho" (UNESP)

MO - PhD in Statistics, Faculdade de Medicina, Universidade Estadual

Paulista "Júlio de Mesquita Filho" (UNESP)

MDB - PhD in Science, Faculdade de Medicina, Universidade Estadual

Paulista "Júlio de Mesquita Filho" (UNESP)

Author contributions

Conception and design: SMB, RJT, MDB

Analysis and interpretation: $M B O, M R B, M C A, K R Q$

Data collection: $M B O, M R B, M C A$

Writing the article: $M B O, S M B, M R B, M C A$

Critical revision of the article: $S M B, R J T$

Final approval of the article*: SMB, RJT, MBO, KRQ, MRB, MCA, MO,

MDB

Statistical analysis: $M O$

Overall responsibility: SMB, RJT, MDB

*All authors have read and approved of the final version of the article submitted to J Vasc Bras 